\title{
Chloroform fraction of Euphorbia maculata has antiplatelet activity via suppressing thromboxane $B_{2}$ formation
}

\author{
SE-UK KWON ${ }^{1}$, JI-YOON CHA ${ }^{1}$, HOON-YEON LEE ${ }^{1}$, MINGJIE XIN ${ }^{1}$, SU-JEONG JI ${ }^{2}$, \\ DAE-KI KIM ${ }^{3}$, DO-SIM PARK ${ }^{4}$, MI-KYUNG PYO ${ }^{5}$ and YOUNG-MI LEE ${ }^{1,2}$
}

\begin{abstract}
${ }^{1}$ Department of Oriental Pharmacy, College of Pharmacy, Wonkwang-Oriental Medicines Research Institute, Wonkwang University; ${ }^{2}$ Department of Food Industry Convergence, Wonkwang University, Iksan, Jeonbuk 570-749; ${ }^{3}$ Department of Immunology and Institute of Medical Science, Jeonbuk National University Medical School, Jeonju, Jeonbuk 561-180; ${ }^{4}$ Department of Laboratory Medicine, School of Medicine, Wonkwang University, Iksan, Jeonbuk 570-749;

${ }^{5}$ International Ginseng and Herb Research Institute, Guemsan, Chungbuk 312-804, Republic of Korea
\end{abstract}

Received May 12, 2014; Accepted January 15, 2015

DOI: $10.3892 / \mathrm{mmr} .2015 .3319$

\begin{abstract}
Euphorbia maculata (EM) is a traditionally used antidiarrheal, antibacterial, antifungal and antioxidant agent. However, the effects of EM on platelet activity remain to be elucidated. Therefore, the present study investigated the antiplatelet effect of various EM extract fractions on platelet aggregation in rats. The antiplatelet activity of the EM fractions on collagen or adenosine diphosphate (ADP)-induced platelet aggregation was evaluated in vitro and ex vivo. Thromboxane $\mathrm{B}_{2}\left(\mathrm{TXB}_{2}\right)$ formation, rat-tail bleeding time and coagulation time were also measured. Among the fractions, the chloroform fraction of EM (CFEM) significantly inhibited ADP-induced platelet aggregation in vitro. Furthermore, oral administration of $50 \mathrm{mg} / \mathrm{kg}$ CFEM to rats significantly reduced ADP-induced platelet aggregation without increasing the tail bleeding time or coagulation time. In addition, EM significantly inhibited the level of $\mathrm{TXB}_{2}$ formation in a dose-dependent manner. These results suggest that CFEM exhibits antiplatelet activity, without causing bleeding, via the suppression of $\mathrm{TXB}_{2}$ formation. CFEM may be a type of food which has the potential for preventing cardiovascular disease.
\end{abstract}

\section{Introduction}

Platelets are critical in hemostasis and thrombus formation $(1,2)$. When blood vessels are damaged, diverse types of agonists, including collagen, adenosine diphosphate (ADP), arachidonic acid (AA) and thrombin, are promptly released

Correspondence to: Professor Young-Mi Lee, Department of Oriental Pharmacy, College of Pharmacy, Wonkwang-Oriental Medicines Research Institute, Wonkwang University, 344-2 Sinyong-dong, Iksan, Jeonbuk 570-749, Republic of Korea

E-mail: ymlee@wku.ac.kr

Key words: Euphorbia maculata, antiplatelet, anticoagulant, thromboxane $\mathrm{B}_{2}$, bleeding time and induce platelet aggregation $(3,4)$. However, abnormal platelet activation may cause cardiovascular diseases (CVDs), including ischemic heart disease, thrombosis, stroke, myocardial infarction and atherosclerosis, which are major diseases responsible for human mortality worldwide $(5,6)$. Thus, reducing platelet aggregation is important for limiting atherosclerosis and CVD (7). Consequently, numerous types of drugs, including antiplatelet, anticoagulant and fibrinolytic agents, have been developed to moderate or prevent thrombosis (8).

A number of anti-thrombotic drugs have been developed and used clinically. Acetylsalicylic acid (ASA), which is a direct cyclooxygenase (COX) inhibitor, is generally used to suppress platelet aggregation (9). However, continuous administration of ASA can induce resistance or side effects, including headache, vomiting, gastric ulceration and abdominal pain in numerous patients (10-13). Therefore, studies have been investigating naturally derived antiplatelet agents with a reduced risk of side effects (14-19).

Euphorbia maculata (EM) is an annual plant, which belongs to the family Euphorbiaceae. EM is grown worldwide, including in East Africa, South America, Korea, Japan and China (20). The antidiarrheal, antibacterial, antifungal and antioxidant activities of this plant have been reported, however, to the best of our knowledge, studies on the antiplatelet effect of EM have not yet been conducted (20-23).

In the present study, the antiplatelet activities of EM fractions were investigated in vitro and ex vivo.

\section{Materials and methods}

Materials. Euphorbia maculata (spotted spurge; EM) was provided by Wonkwang Herb Inc. (Jeonbuk, Korea). Collagen, adenosine diphosphate (ADP), AA and thrombin were obtained from Chrono-Log (Havertown, PA, USA). Trisodium citrate tubes were purchased from Greiner Bio-One (Frickenhausen, Germany). ASA, ketamine $\mathrm{HCl}$, xylazine $\mathrm{HCl}, \beta$-nicotinamide adenine dinucleotide ( $\beta$-NADH), ethylenediaminetetraacetic acid (EDTA), indomethacin, pyruvic acid and sodium chloride were purchased from Sigma-Aldrich (St. Louis, MO, USA). A 
thromboxane $\mathrm{B}_{2}\left(\mathrm{TXB}_{2}\right)$ enzyme immunoassay (EIA) kit was purchased from Enzo Life Sciences (Farmingdale, NY, USA).

Animals. Male Sprague Dawley (SD) rats weighing 250-280 g were obtained from Samtaco Co., Ltd. (Osan, Korea). All the animals were maintained under standard laboratory conditions and allowed free access to food and water ad libitum. The specific pathogen-free animal room was maintained at a temperature of $23 \pm 2^{\circ} \mathrm{C}$ with a humidity of $60 \pm 5 \%$ in a $12 \mathrm{~h}$ light/dark cycle. All animal experimentation protocols used in the present study were approved by the Animal Experiments Committee of Wonkwang University (Iksan, Korea).

Preparation of EM fractions. The aerial parts of Euphorbia maculata (100 g) were reflux extracted with ethanol at $80^{\circ} \mathrm{C}$ for $2 \mathrm{~h}$. Following filtration, the residue was re-extracted twice as described above. The combined filtrate was evaporated and lyophilized to obtain the crude extract. The crude extract was further fractionated using chloroform, ethyl acetate, butanol and distilled water. The fractionation scheme is shown in Fig. 1.

Lactate dehydrogenase $(\mathrm{LDH})$ release assay. The cytotoxic activity of the EM fractions was determined by measuring LDH release from the platelets, as described previously with minor modifications $(24,25)$. Briefly, male SD rats were anesthetized by intraperitoneal injection with a mixture of ketamine $\mathrm{HCl}(60 \mathrm{mg} / \mathrm{kg})$ and xylazine $\mathrm{HCl}(10 \mathrm{mg} / \mathrm{kg})$ and blood was collected from the abdominal aorta using a trisodium citrate tube $(3.8 \%, 1: 9, \mathrm{v} / \mathrm{v})$. The collected blood was centrifuged at $120 \mathrm{x}$ g for $10 \mathrm{~min}$ at $37^{\circ} \mathrm{C}$ to prepare rat platelet rich plasma (PRP) and the remaining blood was further centrifuged at $200 \mathrm{x}$ g for $10 \mathrm{~min}$ at $37^{\circ} \mathrm{C}$ to obtain platelet-poor plasma (PPP). The platelet count was adjusted to $3 \times 10^{8}$ platelets $/ \mathrm{ml}$ using PPP as a diluent for use in the LDH release assay.

PRP was incubated at $37^{\circ} \mathrm{C}$ for $10 \mathrm{~min}$ in the presence or absence of the EM fractions and centrifuged at 12,000 $\mathrm{x} g$ for 2 min. To measure LDH leakage, $50 \mu \mathrm{l}$ aliquots of PRP were collected and mixed with $200 \mu 1$ of $\beta$-NADH solution $(0.03 \%$ $\beta$-NADH in phosphate buffer) and $50 \mu \mathrm{l}$ of pyruvate solution $(22.7 \mathrm{mM})$ at room temperature. The reductions in absorbance due to the conversion of NADH to $\mathrm{NAD}^{+}$were measured using a spectrophotometer (SpectraMax M2; Molecular Devices, Sunnyvale, CA, USA) at a wavelength of $340 \mathrm{~nm}$. LDH release was measured in platelets lysed with $0.2 \%$ Triton X-100 and expressed as a percentage of the total enzyme activity.

In vitro platelet aggregation assay. Male SD rats were anesthetized by intraperitoneal injection with a mixture of ketamine $\mathrm{HCl}$ and xylazine $\mathrm{HCl}$ and blood was collected from the abdominal aortas using trisodium citrate tubes $(3.8 \%, 1: 9$, $\mathrm{v} / \mathrm{v})$. The collected blood was centrifuged at $120 \mathrm{x}$ g for $10 \mathrm{~min}$ to obtain PRP and PPP. The platelet count was adjusted to $3 \times 10^{8}$ platelets $/ \mathrm{ml}$ for the platelet aggregation assay.

Platelet aggregation was measured using turbidimetric methods with minor modifications $(26,27)$. Briefly, PRP was preincubated with or without various concentrations of the $\mathrm{EM}$ fractions for $5 \mathrm{~min}$ at $37^{\circ} \mathrm{C}$. Platelet aggregation was induced by adding $5 \mu \mathrm{M}$ ADP and $3 \mu \mathrm{g} / \mathrm{ml}$ collagen. The

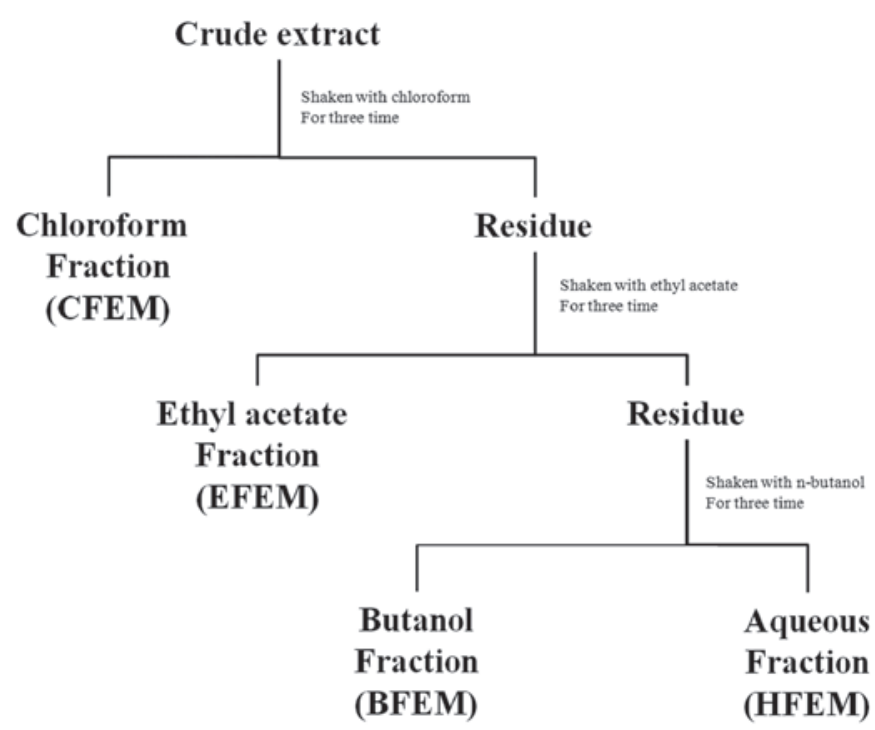

Figure 1. Fractionation scheme of Euphorbia maculata extracts.

quantity of light transmitted through the sample, as a measure of platelet aggregation, was observed for a further $5 \mathrm{~min}$ at $37^{\circ} \mathrm{C}$ using an aggregometer (Model 700; Chrono-log).

Ex vivo platelet aggregation assay. Male SD rats were divided randomly into three groups of 10 rats each and orally administered water (normal), aspirin (20 mg/kg) or CFEM (2, 10 and $50 \mathrm{mg} / \mathrm{kg}$ ) $2 \mathrm{~h}$ prior to sacrifice. Rats were anesthetized with a mixture of ketamine $\mathrm{HCl}$ and xylazine $\mathrm{HCl}$ by intraperitoneal injection, and blood was collected from the abdominal aortas using trisodium citrate tubes. The collected blood was then centrifuged to obtain PRP and PPP. The platelet aggregation assay was performed as described above.

Ex vivo anticoagulant assay. Prothrombin time (PT) and activated partial thromboplastin time (aPTT) was measured as previously described (27). The coagulation assay was performed using PPP from CFEM-treated rats and measured using a coagulometer (Coatron M4; Teco Medical Instruments $\mathrm{GmbH}$, Neufahrn, Germany). Determination of aPTT and PT were performed according to the manufacturer's instructions. For the PT assay, $25 \mu \mathrm{l}$ of PPP was incubated for $1.5 \mathrm{~min}$ at $37^{\circ} \mathrm{C}$. The assay reaction was started by adding $50 \mu \mathrm{l}$ of PT reagent and observed for $3 \mathrm{~min}$. For the aPTT assay, $25 \mu \mathrm{l}$ of PPP was preincubated with $25 \mu \mathrm{l}$ of the aPTT reagent for $5 \mathrm{~min}$ at $37^{\circ} \mathrm{C}$. Subsequently, the assay reaction was initiated by adding $25 \mu \mathrm{l}$ of $25 \mathrm{mM} \mathrm{CaCl}_{2}$ and observed for $5 \mathrm{~min}$ at $37^{\circ} \mathrm{C}$. The clotting time was determined as being the time required to achieve a $50 \%$ change in the scattered light transmission as measured at $660 \mathrm{~nm}$.

Tail bleeding time. Bleeding time was measured as described with minor modifications (28). Rats were anesthetized with ketamine and xylazine. The tail was transected $5 \mathrm{~mm}$ from the tip and promptly immersed in $0.9 \%$ saline at $37^{\circ} \mathrm{C}$. Bleeding time was defined as the time required for the blood flow to stop for at least $30 \mathrm{sec}$. If bleeding continued for $>30 \mathrm{~min}$, the assay was halted and the bleeding time recorded as $30 \mathrm{~min}$ for statistical analysis. 
Measurement of $\mathrm{TXB}_{2}$ formation. PRP $\left(3 \times 10^{8}\right.$ platelets $\left./ \mathrm{ml}\right)$ was preincubated with various concentrations of CFEM for $5 \mathrm{~min}$ and $5 \mu \mathrm{M}$ ADP was added. Subsequently, $50 \mathrm{mM}$ indomethacin and $2 \mathrm{mM}$ EDTA were mixed to stop the reaction. The aliquots were centrifuged at $12,000 \mathrm{xg}$ for $10 \mathrm{~min}$ and the supernatant was collected. $\mathrm{TXB}_{2}$ formation was measured using an EIA kit according to the manufacturer's instructions.

Statistical analysis. The results are presented as the mean \pm standard deviation. Comparisons between groups were performed using Student's t-test and all statistical analyses were performed using SPSS 22.0 software (International Business Machines, Armonk, NY, USA). $\mathrm{P}<0.05$ was considered to indicate a statistically significant difference.

\section{Results}

Effect of EM fractions on LDH release. The cytotoxicity of the EM fractions on rat platelets was investigated by measuring LDH release. As shown in Fig. 2, up to $100 \mu \mathrm{g} / \mathrm{ml}$ of EM extract did not induce LDH release from the platelets. This suggested that the EM fractions did not affect platelet viability or induce platelet lysis in rat plasma.

Effect of EM fractions on platelet aggregation. As shown in Fig. 3, none of the EM fractions affected collagen-induced platelet aggregation. However, CFEM significantly reduced ADP-induced platelet aggregation. When PRP was stimulated by ADP, the aggregation rate was significantly increased from $1.4 \pm 0.71$ to $68.5 \pm 2.12 \%$. Furthermore, CFEM decreased ADP-induced platelet aggregation by $66.4 \pm 3.1,57.0 \pm 4.7$ and $50.2 \pm 1.4 \%$ at 10,30 and $100 \mu \mathrm{g} / \mathrm{ml}$ (Fig. 4).

Effect of CFEM on platelet aggregation in rats. Since CFEM was an effective antiplatelet agent against ADP-induced platelet aggregation in vitro, the effects of CFEM were assessed in an animal model of platelet aggregation induced by ADP. As shown in Fig. 5, the aggregation rate of the untreated rats was $71.73 \pm 4.65 \%$, but was reduced by CFEM treatment. In rats treated with 2, 10 and $50 \mathrm{mg} / \mathrm{kg}$ of CFEM, ADP-induced platelet aggregation was decreased to $67.33 \pm 5.20,61.50 \pm 2.59$ and $51.25 \pm 1.13 \%$, respectively.

Effect of CFEM on tail bleeding time in rats. Fig. 6 shows the effect of CFEM on bleeding time in rats. The bleeding time of untreated rats was $824 \pm 120.32 \mathrm{sec}$ and was significantly increased to $1557 \pm 165.61 \mathrm{sec}$ in aspirin-treated rats. The tail bleeding time of rats treated with 2,10 and $50 \mathrm{mg} / \mathrm{kg}$ CFEM was $901 \pm 57.56,1020 \pm 120.79$ and $1044 \pm 86.53 \mathrm{sec}$, respectively.

Effect of CFEM on coagulation time in rats. As shown in Table I, CFEM did not extend the coagulation time in rats. The PT of untreated rats was $24.4 \pm 0.45 \mathrm{sec}$ and the coagulation times of rats treated with 2,10 and $50 \mathrm{mg} / \mathrm{kg}$ of CFEM were $24.5 \pm 0.34,25.0 \pm 0.44$ and $24.9 \pm 0.52 \mathrm{sec}$, respectively. In addition, the aPTT of CFEM-treated rats was $18.8 \pm 1.07,19.3 \pm 0.74$ and $18.6 \pm 0.52 \mathrm{sec}$, which was not significantly different compared with the untreated rats $(18.9 \pm 0.63 \mathrm{sec})$.

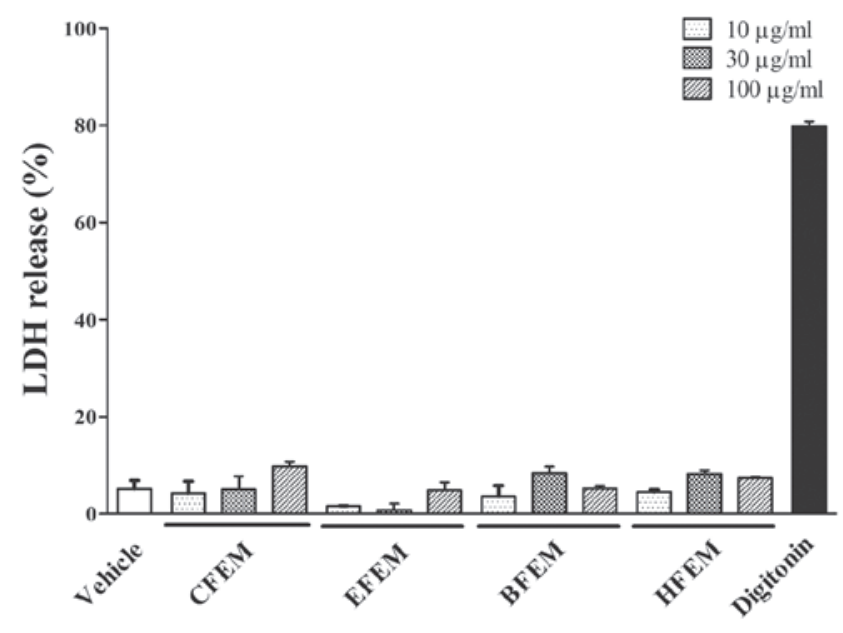

Figure 2. Effects of EM fractions on LDH release. PRP $\left(3 \times 10^{8}\right.$ platelets $\left./ \mathrm{ml}\right)$ was incubated with or without various doses of the EM fractions for $10 \mathrm{~min}$ at $37^{\circ} \mathrm{C}$ and centrifuged at $12,000 \mathrm{x}$ g for $2 \mathrm{~min}$. Released $\mathrm{LDH}$ was measured using a spectrophotometer. Data are expressed as the mean \pm standard deviation. LDH, lactate dehydrogenase; EM, Euphorbia maculata; PRP, platelet rich plasma; CFEM, chloroform fraction of EM; EFEM, ethyl acetate fraction of EM; BFEM, butanol fraction of EM; HFEM, aqueous fraction of EM.

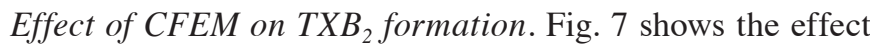
of CFEM on $\mathrm{TXB}_{2}$ formation. ADP increased the level of generated $\mathrm{TXB}_{2}$ to approximately three times that of the control and was reduced in a dose-dependent manner by CFEM. ADP-induced PRP produced $24.64 \pm 0.319 \mathrm{ng} / \mathrm{ml}$ of $\mathrm{TXB}_{2}$ and 10,30 and $100 \mu \mathrm{g} / \mathrm{ml}$ of CFEM decreased $\mathrm{TXB}_{2}$ to $23.80 \pm 0.647,21.48 \pm 1.337$ and $13.73 \pm 0.432 \mathrm{ng} / \mathrm{ml}$, respectively.

\section{Discussion}

In the present study, the inhibitory effect of our EM fractions on collagen- and ADP-induced platelet aggregation in rat plasma was evaluated.

Platelet activation and aggregation have pivotal roles in the pathogenesis of thrombotic complications, including atherosclerosis, myocardial infarction, thromboembolism and other vascular diseases $(2,29)$. Thus, reducing platelet hyperactivation and aggregation is directly connected to the treatment of thrombotic disease in the clinic (30). Anti-coagulating agents are widely used to effectively inhibit platelet aggregation and prevent cardiovascular events. However, continuous use of these agents is prohibited due to adverse effects, including an increased likelihood of a bleeding event $(9,13)$. For this reason, there has been several attempts to overcome these limitations in atherothrombosis treatment and substitute antiplatelet agents, including ADP-receptor agonists, are recommended, as has been demonstrated in numerous clinical trials (31).

In the resting state, platelets freely flow through blood vessels. However, when platelets adhere to damaged vessels, platelet activation and aggregation promptly occur. This process is stimulated by endogenous agonists, including ADP, thrombin, collagen, serotonin, $\mathrm{TXA}_{2}$ and AA (32). Although weak, ADP is the most important mediator among these, as it causes alterations in platelet shape, aggregation and $\mathrm{TXA}_{2}$ secretion (33). $\mathrm{ADP}$, along with adenosine triphosphate and serotonin, is stored in dense granules inside of platelets and is secreted at sites of injury by platelet activation. The released ADP binds to the puri- 

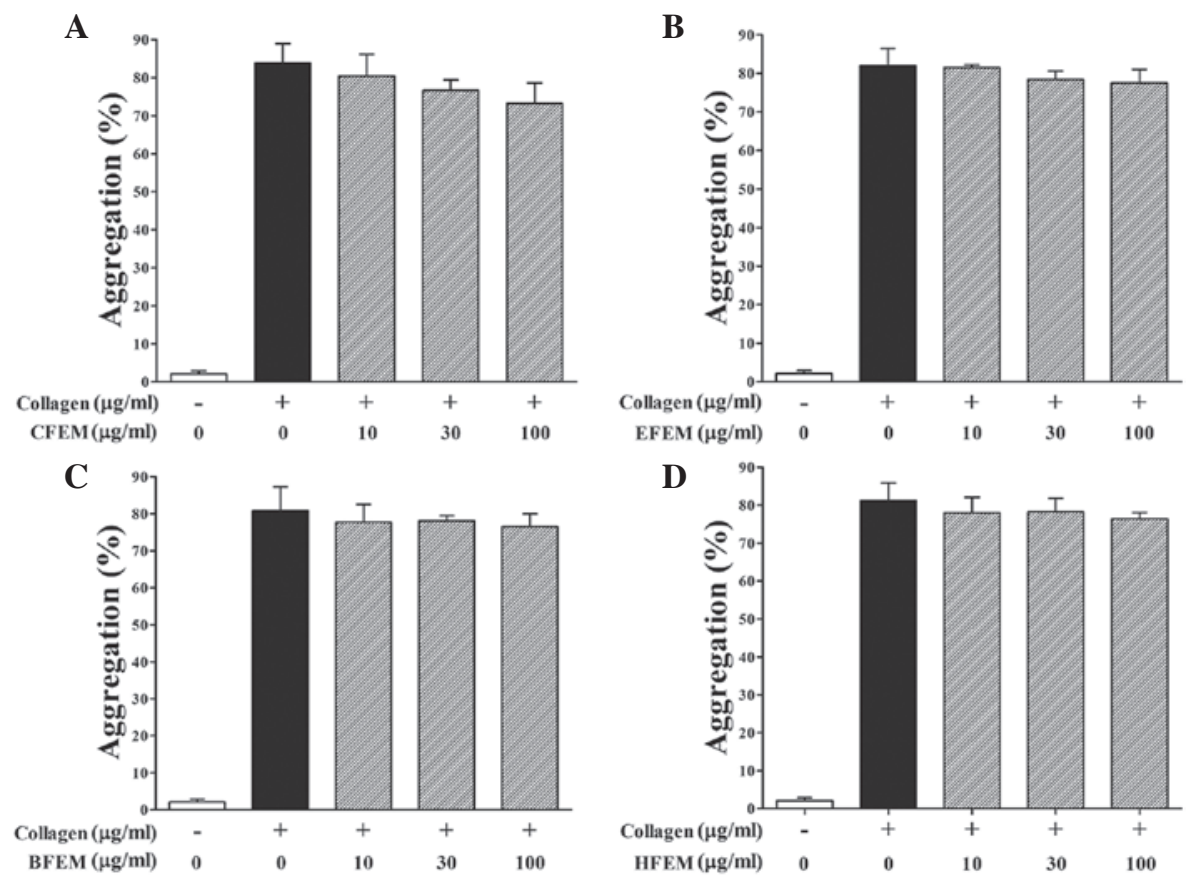

Figure 3. Effects of EM fractions on collagen-induced platelet aggregation in vitro. PRP (3x10 $0^{8}$ platelets $\left./ \mathrm{ml}\right)$ was preincubated with various concentrations of the EM fractions at $37^{\circ} \mathrm{C}$ for $5 \mathrm{~min}$. Collagen $(3 \mu \mathrm{g} / \mathrm{ml})$ was then added to induce platelet aggregation. (A) CFEM; (B) EFEM; (C) BFEM; (D) HFEM. Data are expressed as the mean \pm standard deviation of three experiments. " $\mathrm{P}<0.05$, compared with the control. EM, Euphorbia maculata; $\mathrm{PRP}$, platelet rich plasma; CFEM, chloroform fraction of EM; EFEM, ethyl acetate fraction of EM; BFEM, butanol fraction of EM; HFEM, aqueous fraction of EM.
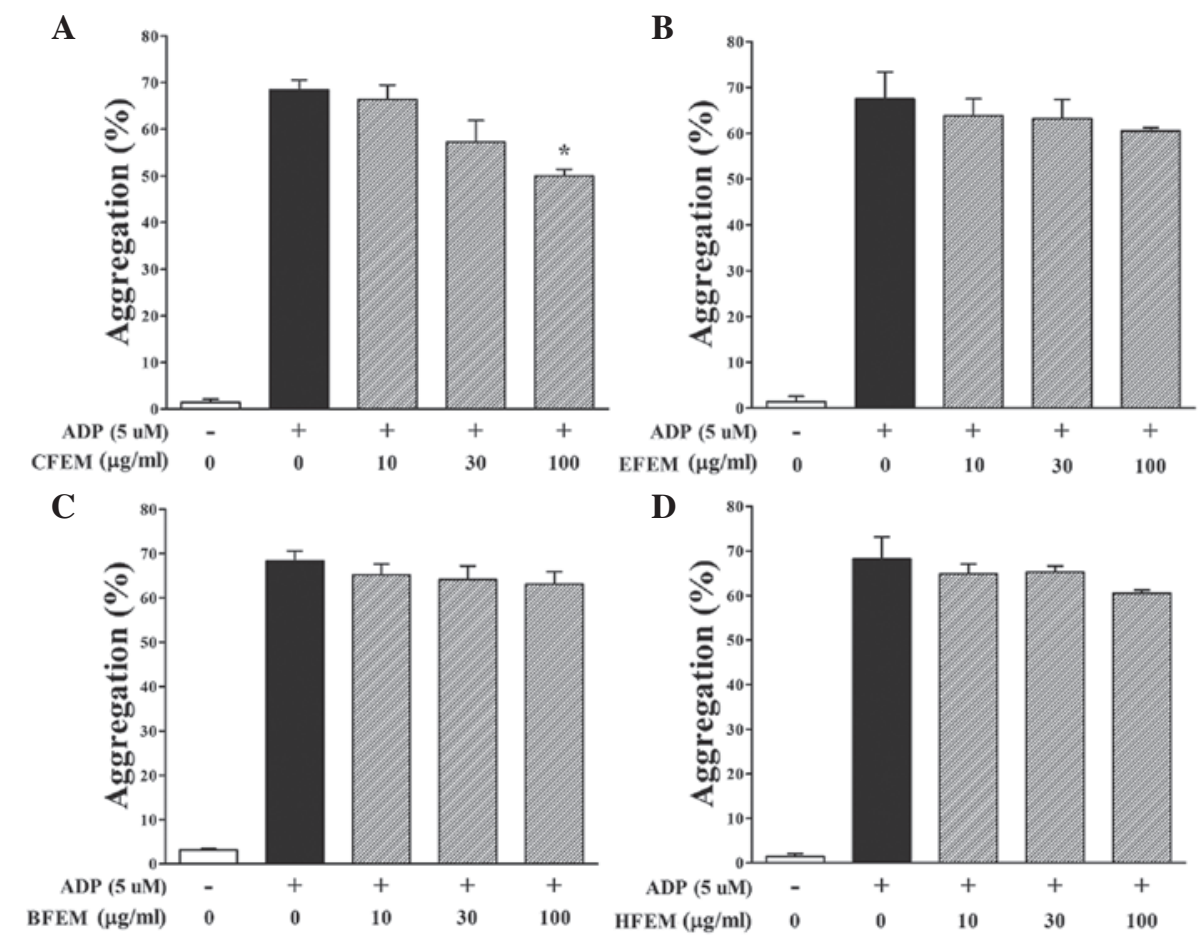

Figure 4. Effects of EM fractions on ADP-induced platelet aggregation in vitro. PRP was preincubated with various concentrations of the EM fractions at $37^{\circ} \mathrm{C}$ for $5 \mathrm{~min}$. ADP $(5 \mu \mathrm{M})$ was then added to induce platelet aggregation. (A) CFEM; (B) EFEM; (C) BFEM; (D) HFEM. Data are expressed as the mean \pm standard deviation of three experiments. ${ }^{*} \mathrm{P}<0.05$, compared with the control. EM, Euphorbia maculata; PRP, platelet rich plasma; CFEM, chloroform fraction of EM; EFEM, ethyl acetate fraction of EM; BFEM, butanol fraction of EM; HFEM, aqueous fraction of EM; PRP, platelet rich plasma; ADP, adenosine diphosphate.

nergic receptors $\mathrm{P} 2 \mathrm{Y}_{1}$ and $\mathrm{P} 2 \mathrm{Y}_{12}$. Activation of the $\mathrm{P} 2 \mathrm{Y}_{1}$ receptor pathway triggers intracellular calcium mobilization and alters platelet shape, while $\mathrm{P} 2 \mathrm{Y}_{12}$ receptor activation inhibits adenylyl cyclase-dependent cyclic adenosine monophosphate generation and prolongs platelet aggregation (34). The antiplatelet agents currently in use (e.g. clopidogrel, ticagrelor and prasugrel) effectively reduce platelet aggregation by inhibiting ADP-P2 $\mathrm{Y}_{12}$ receptor binding (35-38). In the present study, CFEM reduced collagen and ADP-induced platelet aggregation in vitro and CFEM-administered rats decreased ADP-triggered platelet 
Table I. Effect of CFEM on coagulation time in rats.

\begin{tabular}{lccr}
\hline Group & Dose $(\mathrm{mg} / \mathrm{kg})$ & PT (sec) & aPTT (sec) \\
\hline Normal & & $24.4 \pm 0.45$ & $18.9 \pm 0.63$ \\
Aspirin & 20 & $25.6 \pm 0.92$ & $18.7 \pm 0.98$ \\
CFEM & 2 & $24.5 \pm 0.34$ & $18.8 \pm 1.07$ \\
& 10 & $25.0 \pm 0.44$ & $19.3 \pm 0.74$ \\
& 50 & $24.9 \pm 0.52$ & $18.6 \pm 0.52$
\end{tabular}

Data are expressed as the mean \pm standard deviation $(\mathrm{n}=10)$. CFEM, chloroform fraction of EM; PT, prothrombin time; aPTT, activated partial thromboplastin time.

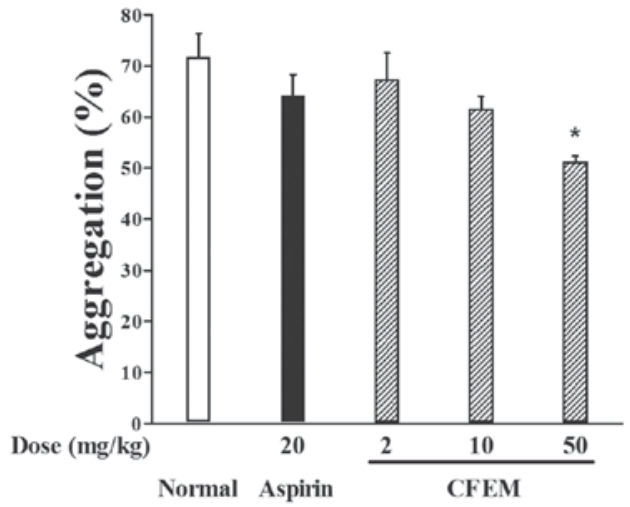

Figure 5. Effects of CFEM on ADP-induced platelet aggregation in rats. Platelet rich plasma was mixed with $\operatorname{ADP}(5 \mu \mathrm{M})$ and platelet aggregation was observed turbidimetrically. Data are expressed as the mean \pm standard deviation $(n=10)$. ${ }^{*} \mathrm{P}<0.05$, compared with the normal group. CFEM, chloroform fraction of EM; ADP, adenosine diphosphate.

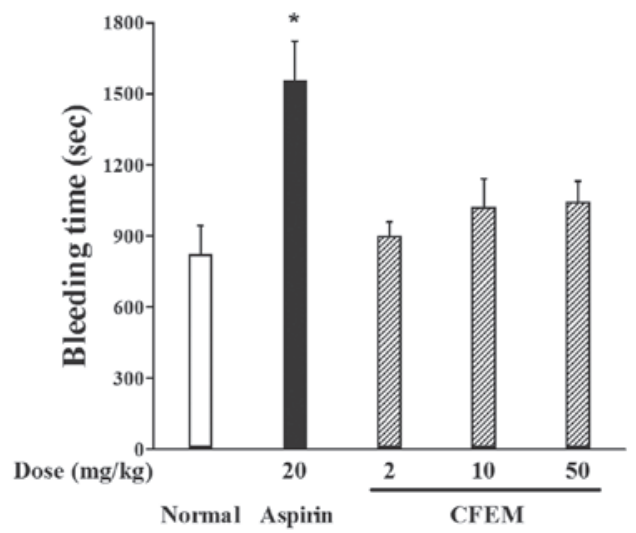

Figure 6. Effects of CFEM on tail bleeding time in rats. Rats were anesthetized using ketamine $\mathrm{HCl}(60 \mathrm{mg} / \mathrm{kg})$ and xylazine $\mathrm{HCl}(10 \mathrm{mg} / \mathrm{kg})$. Subsequently, the tail was transected $5 \mathrm{~mm}$ from the tip and rapidly submerged in saline at $37^{\circ} \mathrm{C}$. Data are expressed as the mean \pm standard deviation $(n=10) .{ }^{*} \mathrm{P}<0.05$, compared with the normal group. CFEM, chloroform fraction of EM.

aggregation in a dose-dependent manner ex vivo. These results suggest that CFEM exerts antiplatelet activity particularly on ADP-induced platelet aggregation.

Normal homeostasis relies on the balance between procoagulation and anticoagulant activities (39). When these activities favor anticoagulant effects or procoagulation effects, continuous bleeding is likely to occur (40). The bleeding time,

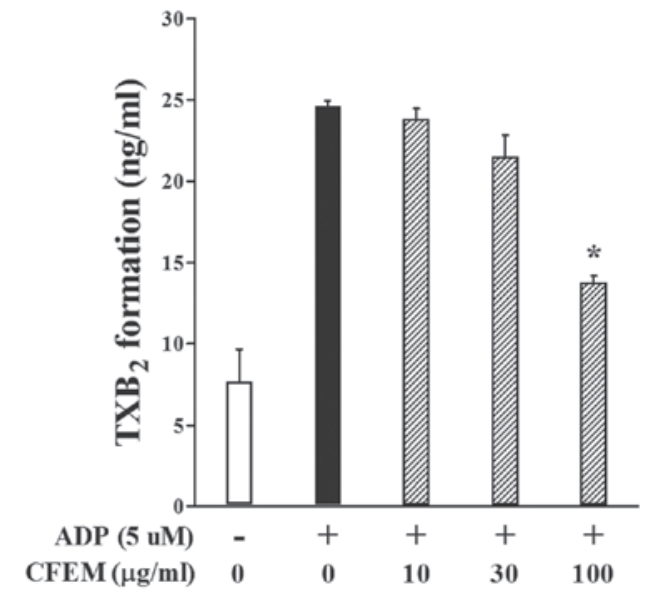

Figure 7. Effects of CFEM on $\mathrm{TXB}_{2}$ formation in rat PRP. PRP $\left(3 \times 10^{8}\right.$ platelets $/ \mathrm{ml})$ was preincubated with 10,30 and $100 \mu \mathrm{g} / \mathrm{ml}$ of CFEM at $37^{\circ} \mathrm{C}$ for 5 min and then $\operatorname{ADP}(5 \mu \mathrm{M})$ was added. $\mathrm{TXB}_{2}$ formation was measured using an enzyme immunoassay kit. Data are expressed as the mean \pm standard deviation of triplicate experiments. ${ }^{*} \mathrm{P}<0.05$, compared with the control. CFEM, chloroform fraction of EM; ADP, adenosine diphosphate; PRP, platelet rich plasma; $\mathrm{TXB}_{2}$, thromboxane $\mathrm{B}_{2}$.

as determined using the tail-transection assay is a well-recognized index of hemostasis and is used to investigate clinically important adverse effects of anticoagulants $(41,42)$. CFEM did not demonstrate significant alterations in bleeding time, which is the main adverse effect of antiplatelet treatment. Thus, this suggested that CFEM treatment is unlikely to produce uncontrollable bleeding.

Coagulation is the consequence of a complex process that occurs by intrinsic, extrinsic and common pathways. Thus, blood coagulation is highly associated with platelet interactions with coagulation factors and blood vessels (43). When measuring coagulation, the PT assay is used to evaluate the extrinsic pathway and the aPTT assay measures the activation of the intrinsic pathway. These tests are recognized as useful methods to confirm bleeding risk and the potential for thrombotic adverse effects $(44,45)$. The anticoagulant activities of CFEM were examined using the coagulation assays and CFEM did not affect PT and aPTT.

A TXA $_{2}$-mediated pathway is also important in antiplatelet treatments. During platelet aggregation, AA is liberated from the platelet plasma membrane and promptly metabolized to $\mathrm{TXA}_{2}$ via the COX and thromboxane A2 synthase pathway (46). $\mathrm{TXA}_{2}$ acts to amplify the intracellular signals for platelet aggregation, 
vasoconstriction and recruitment of platelets (47). In addition, $\mathrm{P} 2 \mathrm{Y}$ receptor activation, in turn, stimulates $\mathrm{TXA}_{2}$ receptor activation, which triggers ADP secretion $(48,49)$. This suggests that $\mathrm{TXA}_{2}$ formation is closely associated with ADP-induced platelet aggregation and agents that reduce $\mathrm{TXA}_{2}$ secretion may be therapeutically useful in platelet-associated CVDs. However, $\mathrm{TXA}_{2}$ has an extremely short half-life and is unstable; therefore, $\mathrm{TXB}_{2}$ levels are assessed as a measure of TXA formation (50). CFEM significantly decreased the level of $\mathrm{TXB}_{2}$ suggesting that suppression of $\mathrm{TXB}_{2}$ formation is associated, in part, to the inhibitory effect of CFEM on platelet aggregation.

In conclusion, CFEM inhibits ADP-induced platelet aggregation by reducing $\mathrm{TXB}_{2}$ formation, without affecting bleeding time or the coagulation pathways. These results suggest that CFEM possesses antiplatelet activity and may be a useful therapeutic for thrombotic disease.

\section{Acknowledgements}

This study was supported by grants from Wonkwang University in 2012.

\section{References}

1. Packham MA and Mustard JF: The role of platelets in the development and complication of atherosclerosis. Semin Hematol 23 8-26, 1986

2. Ruggeri ZM: Mechanisms initiating platelet thrombus formation. Thromb Haemost 78: 611-616, 1997.

3. Ruggeri ZM: Platelets in atherothrombosis. Nat Med 8: 1227-1234, 2002.

4. Brass LF: Thrombin and platelet activation. Chest 124 (Suppl 3): 18S-25S, 2003

5. Lindholm LH and Mendis S: Prevention of cardiovascular disease in developing countries. Lancet 370: 720-722, 2007.

6. Furie B and Furie BC: Mechanisms of thrombus formation. N Engl J Med 359: 938-949, 2008.

7. Gross PL and Weitz JI: New antithrombotic drugs. Clin Pharmacol Ther 86: 139-146, 2009.

8. Collins B and Hollidge C: Antithrombotic drug market. Nat Rev Drug Discov 2: 11-12, 2003.

9. Gaglia MA Jr, Manoukian SV and Waksman R: Novel antiplatelet therapy. Am Heart J 160: 595-604, 2010.

10. Fong J, Cheng-Ching E, Hussain MS, Katzan I and Gupta R: Predictors of biochemical aspirin and clopidogrel resistance in patients with ischemic stroke. J Stroke Cerebrovasc Dis 20: 227-230, 2011.

11. Fitzgerald R and Pirmohamed M: Aspirin resistance: effect of clinical, biochemical and genetic factors. Pharmacol Ther 130: 213-225, 2011.

12. Barrett NE, Holbrook L, Jones S, et al: Future innovations in antiplatelet therapies. Br J Pharmacol 154: 918-939, 2008

13. Jackson SP and Schoenwaelder SM: Antiplatelet therapy: in search of the 'magic bullet'. Nat Rev Drug Discov 2: 775-789, 2003.

14. Angiolillo DJ, Fernandez-Ortiz A, Bernardo E, et al: Variability in individual responsiveness to clopidogrel: clinical implications, management, and future perspectives. J Am Coll Cardiol 49, 1505-1516, 2007.

15. Tsai IL, Lin WY, Teng CM, et al: Coumarins and antiplatelet constituents from the root bark of Zanthoxylum schinifolium. Planta Med 66, 618-623, 2000

16. Ballabeni V, Tognolini M, Bertoni S, et al: Antiplatelet and antithrombotic activities of essential oil from wild Ocotea quixos (Lam.) Kosterm. (Lauraceae) calices from Amazonian Ecuador. Pharmacol Res 55, 23-30, 2007.

17. Seo EJ, Lee DU, Kwak JH, et al: Antiplatelet effects of Cyperus rotundus and its component (+)-nootkatone. J Ethnopharmacol 135: 48-54, 2011.

18. Fuentes E and Palomo I: Relationship between platelet PPARs, cAMP levels, and P-Selectin expression: Antiplatelet activity of natural products. Evid Based Complement Alternat Med 2013: 861786, 2013.
19. Fuentes E, Caballero J, Alarcón M, Rojas A and Palomo I: Chlorogenic acid inhibits human platelet activation and thrombus formation. PLoS One 9: e90699, 2014.

20. Yoshiaki A, Keita K, Tsutomu H, et al: Four new hydrolysable tannins and an acylated flavonol glycoside from Euphorbia maculate. Can J Chem 75: 727-733, 1997.

21. Cao X, Wang W, Zhou L, Cui X and Song X: Comparison on mass fraction of total flavonoids and tannin of three kinds of herba Euphorbiae Humifusae and their antibacaterial activity in vitro. Acta Agriculturae Boreali-Occidentalis Sinica 21: 184-188, 2012

22. Kuerbannisha M, Zulipiya T, Gulina D, Xieraili T and Silafu A: Determination of rutin and quercitrin in the antifungal extract from Euphorbia maculate. Lishizhen Medicine and Materia Medica Research 22: 2584-2585, 2011.

23. Liu S, Jiang D and Li L: Research on the total flavonoids content and antioxidant activity of Euphorbia maculata and Euphorbia humifusae. J Hunan Agr U Nat Sci 33: 287-288, 2007

24. Lee BK, Lee DH, Park S, et al: Effects of KR-33028, a novel $\mathrm{Na}^{+} / \mathrm{H}^{+}$exchanger-1 inhibitor, on glutamate-induced neuronal cell death and ischemia-induced cerebral infarct. Brain Res 1248: 22-30, 2009.

25. Ryu KH, Han HY, Lee SY, et al: Ginkgo biloba extract enhances antiplatelet and antithrombotic effects of cilostazol without prolongation of bleeding time. Thromb Res 124: 328-334, 2009.

26. Mustard JF, Perry DW, Ardlie NG and Packham MA: Preparation of suspensions of washed platelets from humans. Br J Haematol 22: 193-204, 1972.

27. LeeBJ,JoIY,Bu Y,etal: Antiplateleteffect of Spatholobus suberectus via inhibition of glycoprotein $\mathrm{II}_{\mathrm{b}} / \mathrm{III}_{\mathrm{a}}$ receptor. J Ethnopharmacol 134: 460-467, 2011.

28. Cho J, Furie BC, Coughlin SR and Furie B: A critical role for extracellular protein disulfide isomerase during thrombus formation in mice. J Clin Invest 118: 1123-1131, 2008.

29. Majid A, Delanty N and Kantor J: Antiplatelet agents for secondary prevention of ischemic stroke. Ann Pharmacother 35: 1241-1247, 2001.

30. Wijns W, Kolh P, Danchin N, et al: Guidelines on myocardial revascularization. Eur Heart J 31: 2501-2555, 2010.

31. Albers GW and Amarenco P: Combination therapy with clopidogrel and aspirin: can the cure results be extrapolated to cerebrovascular patients? Stroke 32: 2948-2949, 2001.

32. Jin YR, Hwang KA, Cho MR, et al: Antiplatelet and antithrombotic activities of CP201, a newly synthesized 1,4-naphthoquinone derivative. Vasc Pharmcol 41: 35-41, 2004.

33. Kunapuli SP, Dorsam RT, Kim S and Quinton TM: Platelet purinergic receptors. Curr Opin Pharmacol 3: 175-180, 2003.

34. Hollopeter G, Jantzen HM, Vincent D, Li G, England L and Ramakrishnan V: Identification of the platelet ADP receptor targeted by antithrombotic drugs. Nature 409: 202-207, 2001.

35. Gachet C: P2 receptors, platelet function and pharmacological implications. Thromb Haemost 99: 466-472, 2008.

36. Cattaneo M: Platelet P2 receptors: old and new targets for antithrombotic drugs. Expert Rev Cardiovasc Ther 5: 45-55, 2007.

37. Cattaneo M: New P2Y12 blockers. J Thromb Haemost 7 (Suppl 1): 262-265, 2009.

38. Jakubowski JA, Winters KJ, Naganuma $\mathrm{H}$ and Wallentin L: Prasugrel: a novel thienopyridine antiplatelet agent. A review of preclinical and clinical studies and the mechanistic basis for its distinct antiplatelet profile. Cardiovasc Drug Rev 25: 357-374, 2007.

39. Akiyama H, Kudo S and Shimizu T: The absorption, distribution and excretion of a new antithrombotic and vasodilating agent, cilostazol, in rat, rabbit, dog and man. Arzneimittelforschung 35: 1124-1132, 1985.

40. Li Y and Wang N: Antithrombotic effects of Danggui, Honghua and potential drug interaction with clopidogrel. J Ethnopharmacol 128: 623-628, 2010.

41. Renné T, Nieswandt B and Gailani D: The intrinsic pathway of coagulation is essential for thrombus stability in mice. Blood Cell Mol Dis 36: 148-151, 2006.

42. Azevedo AP, Farias JC and Costa GC, et al: Anti-thrombotic effect of chronic oral treatment with Orbignya phalerata Mart. J Ethnopharmacol 111: 155-159, 2007.

43. Mann KG: Thrombin: can't live without it; probably die from it. Chest 124 (Suppl 3): 1S-3S, 2003.

44. Jennings LK: Mechanisms of platelet activation: need for new strategies to protect against platelet-mediated atherothrombosis. Thromb Haemost 102: 248-257, 2009. 
45. Mitchell MD, Bibby JG, Hicks BR, et al: Thromboxane B2 and human parturition: concentrations in the plasma and production in vitro. J Endocrinol 78: 435-441, 1978.

46. Storey RF, Judge HM, Wilcox RG and Heptinstall S: Inhibition of ADP-induced P-selectin expression and platelet-leukocyte conjugate formation by clopidogrel and the P2Y12 receptor antagonist AR-C69931MX but not aspirin. Thromb Haemost 88: 488-494, 2002.

47. Barton JF, Hardy AR, Poole AW and Mundell SJ: Reciprocal regulation of platelet responses to $\mathrm{P} 2 \mathrm{Y}$ and thromboxane receptor activation. J Thromb Haemost 6: 534-543, 2008.
48. Viinikka L and Ylikorkala O: Measurement of thromboxane B2 in human plasma or serum by radioimmunoassay. Prostaglandins 20 : 759-766, 1980.

49. Plow EF and Ginsberg MH: Cellular adhesion: GPIIb/IIIa as a prototypic adhesion receptor. Prog Hemost Thromb 9: $117-156,1989$.

50. Helft G, Gilard M, Feuvre Le C and Zaman AG: Drug insight: antithrombotic therapy after percutaneous coronary intervention in patients with an indication or anticoagulation. Nat Clin Pract Cardiovasc Med 3: 673-680, 2006. 